\title{
A Folded Waveguide ICRF Antenna for PBX-M and TFTR
}

\author{
T.S. Bigelow, M.D. Carter, C.H. Fogelman, J.J Yugo \\ F.W. Baity, G.L. Bell, W.L. Gardner, R.H. Goulding \\ D.J. Hoffman, P.M. Ryan, D.W. Swain, D.J. Taylor \\ Oak Ridge National Laboraton; Oak Ridge, Tn. 37831 \\ R. Wilson, S. Bernabei, H. Kugel, M. Ono \\ Princeton Plasma Physics Laboratory, Princeton, NJ 08543
}

\begin{abstract}
The folded waveguide (FWG) antenna is an advanced ICRF launcher under development at ORNL that offers many significant advantages over current-strap type antennas. These features are particularly beneficial for reactor-relevant applications such as ITER and TPX. Previous tests of a development folded waveguide with a low density plasma load have shown a factor of 5 increase in power capability over loop antennas into similar plasma conditions. The performance and reliability of a FWG with an actual tokamak plasma load must now be verified for further acceptance of this concept. A $58 \mathrm{MHz}, 4 \mathrm{MW}$ folded waveguide is being designed and built for the PBX-M and TFTR tokamaks at Princeton Plasma Physics Laboratory. This design has a square cross-section that can be installed as either a fast wave (FW) or ion-Bernstein wave (IBW) launcher by $90^{\circ}$ rotation. Two new features of the design are: a shorter quarter-wavelength resonator configuration and a rear-feed input power coupling loop. Loading calculations with a standard shorting plate indicate that a launched power level of $4 \mathrm{MW}$ is possible on either machine. Mechanical and disruption force analysis indicates that bolted construction will withstand the disruption loads. An experimental program is planned to characterize the plasma loading, heating effectiveness, power capability, impurity generation and other factors for both FW and IBW cases. High power tests of the new configuration are being performed with a development FWG unit on RFTF at ORNL.
\end{abstract}

\section{INTRODUCTION}

The FWG [1] is being investigated at ORNL as an advanced antenna for plasma heating in the Ion-Cyclotron Range of Frequencies (ICRF). The FWG launcher consists of a rectangular cavity folded in one direction to fit into available tokamak port dimensions. Power is fed into the cavity at the rear end through a coupling loop and coupled from the cavity into the plasma through slots in the front wall "polarizing plate." The slots in the polarizing plate are placed between alternate vanes so that the radiated magnetic field components are in phase. Although some bumpiness in the antenna pattern results from the shorting plate pattern, these components decrease rapidly away from the plate and FWG patterns resemble current strap antenna patterns with a sinusoidal poloidal field variation. An alternate version of the polarizing plate allows $0-\pi$ launch spectrum phasing by staggering half width slots. The radial length of the FWG is typically a half waveguide wavelength although a shorter quarter wavelength version is also possible. The waveguide wavelength and cutoff frequency are governed by the number of folds or vanes and the outside dimensions. Adding more vanes will lower the cutoff frequency at the expense of higher losses. Typical cavity unloaded $Q$ values range from 1000-3000 and plasma loading reduces Q by up to a factor of 10 .

* Managed by Martin Marietta Energy Systems, Inc., for the U. S. Department of Energy under contract DE-ACO5-840R21400. 


\section{DISCLAIMER}

This report was prepared as an account of work sponsored by an agency of the United States Government. Neither the United States Government nor any agency thereof, nor any of their employees, makes any warranty, express or implied, or assumes any legal liability or responsibility for the accuracy, completeness, or usefulness of any information, apparatus, product, or process disclosed, or represents that its use would not infringe privately owned rights. Reference herein to any specific commercial product, process, or service by trade name, trademark, manufacturer, or otherwise does not necessarily constitute or imply its endorsement, recommendation, or favoring by the United States Government or any agency thereof. The views and opinions of authors expressed herein do not necessarily state or reflect those of the United States Government or any agency thereof. 


\section{DISCLAIMER}

Portions of this document may be illegible in electronic image products. Images are produced from the best available original document. 
The FWG provides the benefits of waveguide type launchers in a range of frequencies where long wavelengths have traditionally required current loop type antennas. The FWG structure has many advantages over loop antennas as an ICRF launcher- especially in reactor type applications [2] such as: very high power density operation, all-metal ceramic-free construction, internal impedance matching, no requirement for a Faraday shield, low internal electric fields near the plasma, improved array performance, and greater plasma-antenna separation. Recent modeling efforts [3] have indicated that an array of 8 FWG's operating in one port of the ITER device would be capable of delivering $>32 \mathrm{MW}$ to the plasma. This represents an increase of 3-4 times the expected capability of an array of loop antennas in the same port.

Previously, high power FWG proof-of-principle tests were conducted on the Radio Frequency Test Facility (RFTF) at ORNL into a low density plasma. A record high unloaded power level of $1 \mathrm{MW}$ was achieved as well as indications of good loading even for the low plasma density involved. A demonstration of the FWG's capabilities on an actual tokamak plasma is needed to further validate the FWG concept; therefore a collaboration has been established between ORNL and PPPL to build and test a folded waveguide on the PBX-M and/or TFTR tokamaks.

Several improvements to the basic FWG design and analysis techniques have recently been developed such as a shorter quarter-wavelength design and a rear feed point configuration. The quarter waveguide wavelength $(\lambda \mathrm{g} / 4)$ configuration is nearly half the length of the original half wave design and is particularly useful for operating in smaller ports with a waveguide close to cutoff. The back end of the $\lambda \mathrm{g} / 4$ design consists of an open circuit formed by ending the vanes and allowing the cutoff outer box to continue on $\sim 2$ e-folding lengths. Equivalent network and rectangular cavity models have been developed for analysis of the FWG internal fields. Codes originally written for loop antenna modeling have been adapted to the FWG allowing relatively accurate predictions of plasma loading.

\section{THE PBX-M / TFTR FWG DESIGN}

A $58 \mathrm{MHz}, 4 \mathrm{MW}, 12$ vane FWG with a quarter wavelength resonator has been designed and is being fabricated for PBX-M and/or TFTR. This design has square cross section that will allow both fast wave and ion-Bernstein wave launch by rotating the device $90^{\circ}$. This frequency was chosen to allow $2 \Omega_{\mathrm{H}}$ fast wave and IBW heating on PBX and is compatible with a number of heating scenarios on TFTR between 3.7 and 5.6 T. The waveguide cross section dimensions of $0.31 \mathrm{x}$ $0.31 \mathrm{~m}$ are set by the available port size on PBX-M. The vanes consist of $6.35 \mathrm{~mm}$ thick sheets with the edges and corners rounded to reduce electric field enhancement. The overall length of this design is $2.33 \mathrm{~m}$ including a $0.4 \mathrm{~m}$ cutoff rear extension section. A construction technique using largely bolted assembly was selected to facilitate later modifications. Extensive mechanical, thermal and disruption force modeling has been performed for this FWG and indicates that stainless steel is sufficiently strong to be used throughout. Surfaces that carry if current will be copper plated. The polarizing plate is attached with a large number of recessed screws and has a slight curvature to match the ripple-corrected toroidal curvature of the device. Graphite bumpers will be attached to all sides of the FWG face plate to provide particle flux protection for both IBW and fast wave orientations. Plasma facing surfaces will be coated with boron carbide to a thickness of $10-100 \mu \mathrm{m}$. 
The FWG is enclosed in a $0.5 \mathrm{~m}$ diameter vacuum duct as shown in figure 1 . A gate valve is being installed on the vacuum enclosure so that changes can be made to the waveguide without affecting the tokamak vacuum. To clear the gate valve, the FWG must move radially nearly $1.4 \mathrm{~m}$. Several sets of rollers are provided inside the vacuum tank (in two planes). The coax feedline must also accommodate the radial motion so a rear-feed technique was developed which allows the coax to retract straight back inside a long bellows.

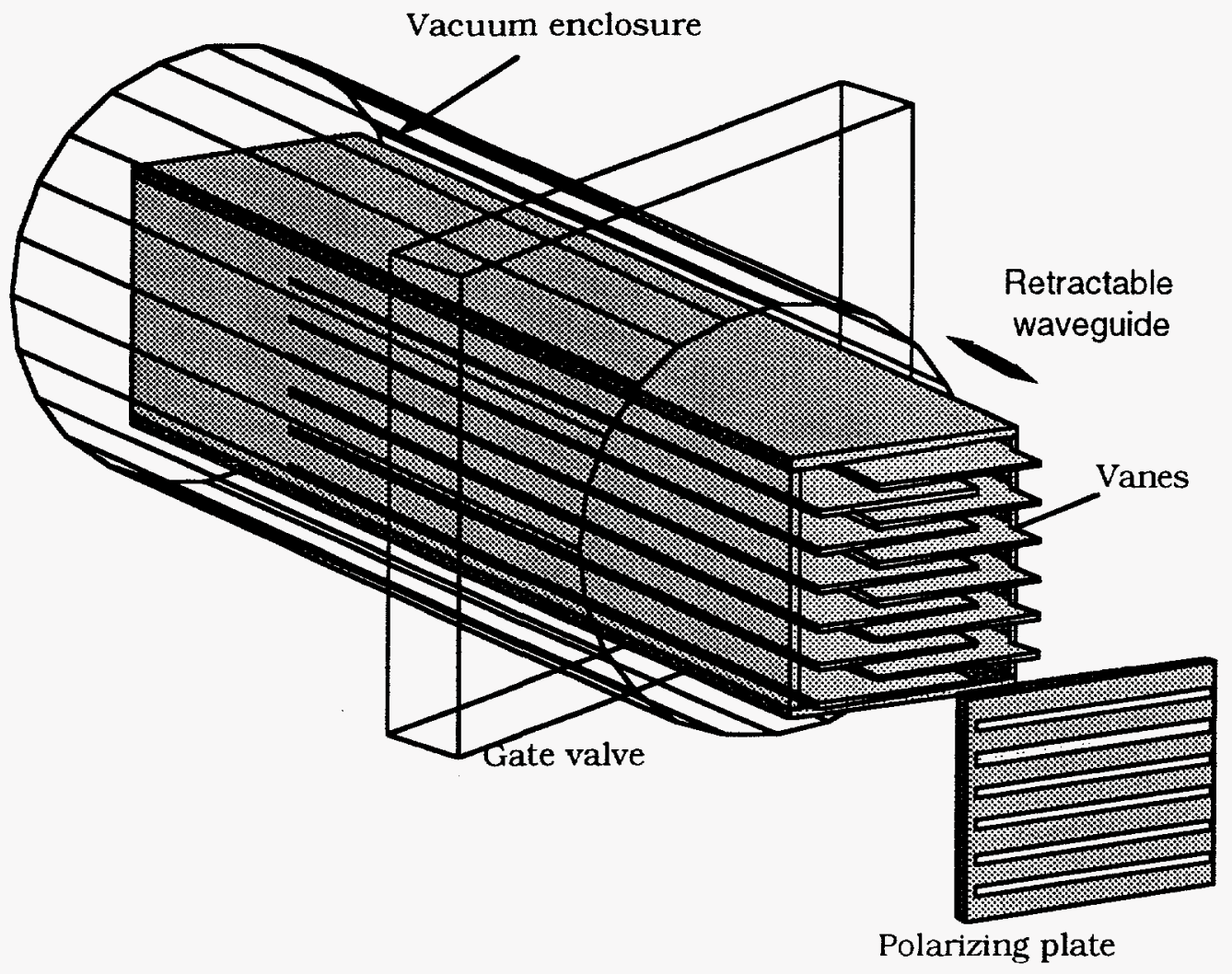

Figure 1 Front view of the PBX/TFTR folded waveguide

The input coax feeds into the cutoff waveguide extension where a coupling loop is formed between the center conductor and outer conductor by connecting a current strap between the center and the side wall as shown in figure 2. A large sliding fingerstock joint connects the outer conductor to the back wall. By radial adjustment, the area of the coupling loop can be changed for input impedance matching.

A number of rf modeling techniques have been developed for analyzing FWG designs. The effective waveguide width is needed to design the resonant frequency and is obtained by unfolding the waveguide and adding vane tip correction factors for path length and electric field enhancement. The unfolded rectangular cavity has analytic field distributions which are useful for estimating $\mathrm{Q}$, losses, efficiency, magnetic fields, surface currents, and electric fields. Using these models, an unloaded Q of 1400 is predicted for this design. The effect of the shorting plate apertures and plasma loading can be modeled by increasing the surface resistivity of the shorting plate wall. The vane-tip field enhancement factor was calculated using an electrostatic finite difference Laplace solver code which predicts $\sim 2.34$ for the 
PBX case. If a maximum electric field exists of $44 \mathrm{kV} / \mathrm{cm}$ at the central vane tip, the vane-to-vane field will be $19 \mathrm{kV} / \mathrm{cm}$. With this electric field, the cavity model predicts a peak wall magnetic field of 0.0043 Tesla. The magnetic field seen by the plasma will be slightly reduced from the value inside the cavity. Current from inside the FWG flows on the outside of the polarizing plate to fill in the gaps making a nearly continuous field distribution. The RANT3D code [3] originally developed for current strap antenna loading calculations has been adapted to analyze the FWG by assuming an equivalent face plate current distribution and corresponding magnetic field. A value for power coupled to a plasma for a given if magnetic field is obtained which is $-310 \mathrm{GW} / \mathrm{T}^{2}$ for PBX. For Bmax of $0.0043 \mathrm{~T}$ predicted by the cavity analysis, $5.9 \mathrm{MW}$ of power is coupled to the plasma, and $485 \mathrm{~kW}$ is dissipated in the cavity walls giving an efficiency of $92 \%$.

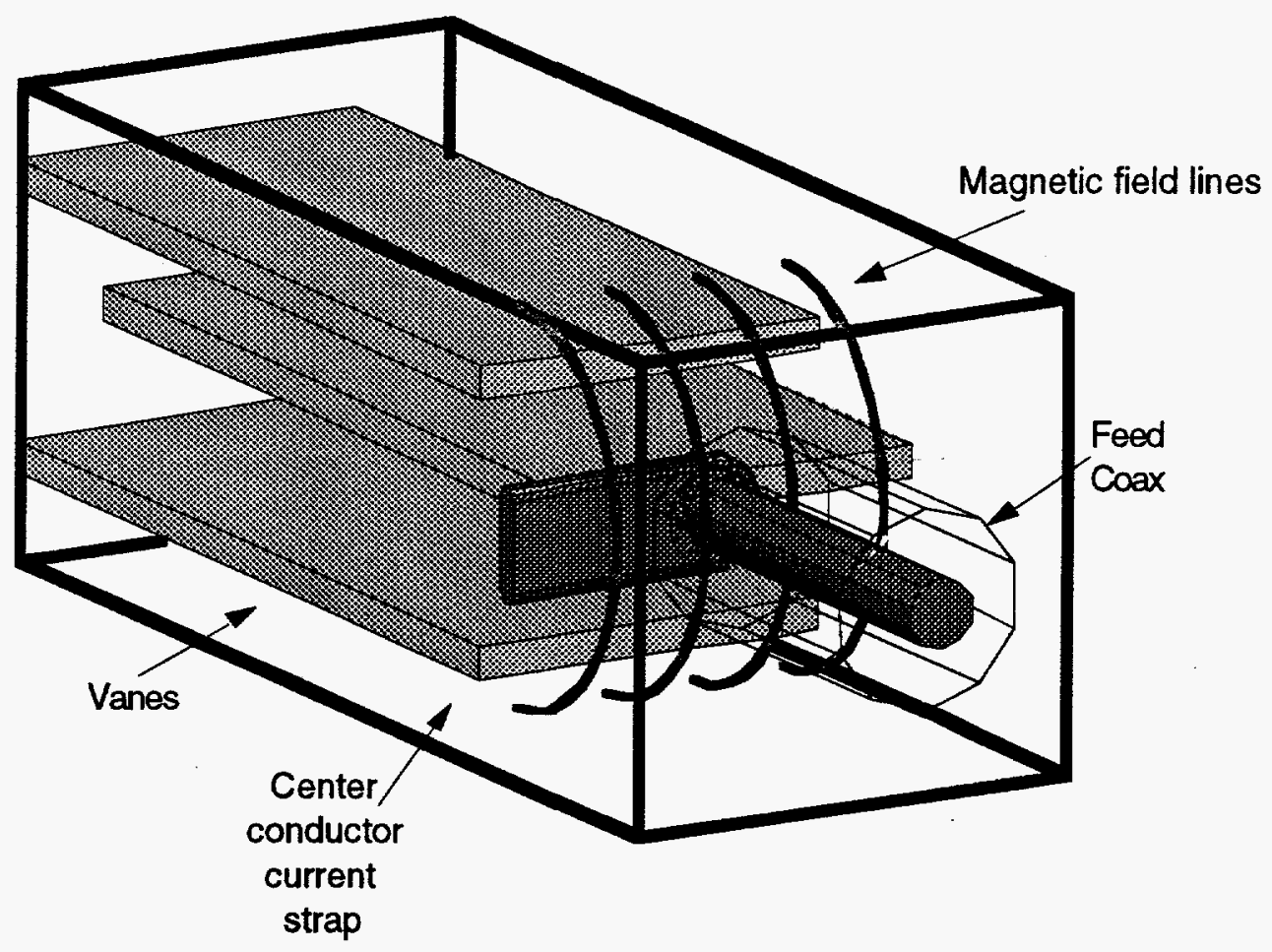

Figure 2 Rear-feed configuration for the quarter wavelength FWG

The mechanical and rf modeling results are quite encouraging at this point in the design. Both low power and high power tests of the new quarter wavelength, rear feed configuration are underway using a $67.5 \mathrm{MHz}$ development unit modified from the earlier half-wavelength development tests. Additional E-field probe, magnetic field pattern measurements, and calculations are planned. High power plasma operation on RFTF with and without internal matching adjustment will be studied as well as conditioning requirements.

The current schedule calls for completion of the PBX FWG fabrication in October 1995 and installation at PPPL in January 1996.

[1] T.L. Owens, IEEE Trans. Plasma Sci.. PS14 (1986) 934-46

[2] G.R. Haste, et al., Fus. Engr and Des. 24 (1994) 191-4

[3] M. D. Carter, et. al. this proceedings 